On trans-scientific turf

\author{
Owen Gingerich
}

Beyond Velikovsky: The History of a

Public Controversy.

By Henry H. Bauer.

University of Illinois Press/Harper \&

Row: 1985. Pp.354. \$21.95, £24.25.

"THE thousands of words spilled to refute and condemn his theories gave them a sort of status, even if only that of divinely inspired nonsense." So the London Times summed up the controversy surrounding the work of Dr Immanuel Velikovsky when he died in November 1979.

Basically, Velikovsky claimed that in the ages before Christ a large body had been ejected from Jupiter and had gone into orbit around the Sun, eventually to become the planet Venus. On its way, it came close enough to the Earth around $1500 \mathrm{BC}$ to cause the pharonic plagues of Exodus and may other miraculous phenomena recorded in the Old Testament, including the day the Sun stood still at Gibeon. Relying on eclectic interpretations of world-wide mythology, Velikovsky amazed his readers with his erudition and dismayed astronomers by his flagrant disregard for Newtonian mechanics.

The hue and cry against Velikovsky's theory came primarily in two waves. When his principal work, Worlds in Collision, appeared in 1950, heralded by sensational abridgements in Harper's, Colliers and the Reader's Digest, astronomers stirred up such a tempest that Velikovsky's place in the best-seller list was assured. Having learned that any publicity is good publicity, the scientists quickly lapsed into indignant silence, hoping that the interest in Velikovsky's theories would atrophy under their careful lack of attention. Their scheme may well have worked except that Velikovsky was "rediscovered" by the anti-establishment generation of the $1960 \mathrm{~s}$, for whom he became something of a folk hero. The scornful attacks of the early 1950 s, and especially tales of a threatened textbook boycott against his publisher, Macmillan, helped build up an image of a scientific martyr, a modern-day Galileo alternately jeered and ignored by the entrenched scientific establishment.

Thus, by 1974 , several of us agreed that a forum should be provided for Velikovsky to meet his scientific critics, and for the scientists to put on the record a clear statement of their objections. The actual encounter, at a meeting of the American Association for the Advancement of Science in San Francisco, proved to be a memorable non-meeting of minds, with a highly polarized audience full of partisans unlikely to be swayed by arguments or counter-arguments from either opposing camp. Scientists who had advocated silence on the matter went away with an "I told you so" attitude. Nevertheless, this second wave of criticism was harder for Velikovsky's supporters to cope with, and Velikovsky felt particularly stung by the witty and articulate attack made by Carl Sagan. In colourful terms, Sagan described such things as the "fly ablation problem", that is, the difficulty of flies originating on the Venus-comet in entering our atmosphere just in time to cause the pharonic plague of pests.

Today, although Velikovsky's catastrophism is rapidly being forgotten, the fierce controversy that swirled for three decades can still teach us something about the nature of science and trans-scientific

\section{Unreal Science}

SIR,-As a qualified and practising soientist I wish to dissociate myself from your editorial of April 12. You allude to Geller and Velikovsky with terms like "nonsenses", "beliefs beyond science", and "pseudo-scientific ideas", and contrast these with "real science" and "science based on conventional ideas about the way a scientific investigation should proceed", and you declare that "scientists want to fight this distressing drift from the scientific way of thinking".

History is littered with ideas shown to be false by people bold enough to question their contemporary conventional science, often in the face of personal ridicule and even persecution.

Presumably you class Einstein's

Passions run high - a letter in Nature, 28 June 1974, in response to an editorial on Velikovsky.

challenges. It is such questions that Henry H. Bauer, Dean of the College of Arts and Sciences at the Virginia Polytechnic Institute, has explored. A personal and somewhat idiosyncratic account, Beyond Velikovsky contains material to infuriate or at least exasperate everybody. Nevertheless, it is the most balanced and informative analysis yet to emerge from the whole affair.

Bauer argues that science does not find absolute truth, but only a high degree of probability. This prevents scientists from claiming that any particular sequence (such as Velikovsky's) is impossible, only that it is staggeringly unlikely. However, Velikovsky never claimed that his scenario was probable, only that it happened. Hence, counter-arguments that it was improbable completely missed the point. Velikovsky was staking his claims on an entirely different turf - "trans-scientific" in Bauer's terminology - and so the normal type of scientific argument lost its force against Velikovsky and his supporters. In their frustration, scientists were frequently reduced to appeals to authority (their own, of course), which went directly counter to their own claims of how science worked.
Velikovsky, too, was frustrated by the resistance from the scientific community, so he consulted his neighbour at Princeton, Albert Einstein, about the status of his theory. Einstein assured him that it would be better if the theory could predict something. Thereafter Velikovsky searched his writings and came up with a series of "advance claims" that he had made, ranging from high temperatures on Venus to radio noise from Jupiter. Unfortunately, Einstein had not made it clear to him (and thus to Velikovsky's followers) that predictions have to be made for the right sorts of reasons to be persuasive. The principles must fit with the coherence of scientific understanding, and they should not be single ad hoc instances incapable of supporting further, related predictions.

Bauer analyses both Velikovsky's physical reasoning and his advance claims, and both are found wanting. Although Velikovsky's scenario cannot be denied outright, it is relatively easy to show that his understanding of physical principles was hopelessly faulty. "There is rarely a certain way of identifying a crank", Bauer cautiously asserts, and only after 150 pages does he label Velikovsky one in the sense of a person "enthusiastically possessed by a particular crotchet or hobby". But in a devastating chapter entitled "A Nontechnical Case against Velikovsky" he leaves no doubt that the enthusiastic $\mathrm{Dr}$ Velikovsky was also a crank in the more pejorative sense of the word.

Nor do Velikovsky's opponents escape Bauer's criticism. "In retrospect", he writes, "it seems clear that Velikovsky's critics did not grasp the magnitude - or perhaps even the nature - of the task of discrediting Velikovsky in the eyes of the public at large''. Bauer charges them with errors of commission - arguing ex cathedra, with ridicule, ad hominem - as well as with errors of omission. In the latter category is, primarily, the failure to capitalize on the unoriginal character of Velikovsky's scheme.

There is, however, one logical path that, curiously enough, Bauer has not explored. Although science cannot prove that a Velikovskian scenario is impossible, it might well prove that it did not happen. At the San Francisco confrontation, Peter Huber provided evidence from Babylonian records that Venus in $1600 \mathrm{BC}$ behaved just as it did in the centuries immediately before our own era. I remarked at the time that if Huber was right (as I certainly believe), Velikovsky's scenario was finished. Velikovsky tossed one of his ad hominem barbs at Huber, labelling him a selfconfessed amateur in Babylonian. Huber, who is one of the world's leading statisticians and a redoubtable cuneiformist on the side, quickly proved on the stage how ignorant Velikovsky himself was of cuneiform languages. The Velikovskyites were naturally reluctant to admit defeat by a single stroke, so they have since worked hard to discredit the Babylonian data, 